\title{
Characterisation of subpopulations and functions in peritoneal leucocytes of Zucker obese rats
}

\author{
N. M. De Castro ${ }^{1}$, I. Baeza ${ }^{1}$, C. Vida ${ }^{1}$, N. Úbeda ${ }^{2}$ and M. De La Fuente ${ }^{1}$ \\ ${ }^{1}$ Department of Physiology, Faculty of Biology, Complutense University of Madrid, 28040 Madrid, Spain and ${ }^{2}$ Department \\ of Pharmaceutical and Food Sciences, Faculty of Pharmacy, San Pablo CEU University, 28668 Madrid, Spain
}

Obesity is one of the most common diseases in developed countries. There is evidence supporting the link between the adipose tissue and both innate and adaptive immune responses ${ }^{(1)}$. Previous studies have demonstrated that several immune functions are good markers of biological age and it is well known that the age-related impairment of immune functions is associated with increased morbidity and mortality ${ }^{(2)}$. Therefore, the aim of the present work was to study different functions of peritoneal leucocytes as well as characterisation of their subpopulations in Zucker obese rats.

Male rats of two different strains (Zucker and Wistar) were used. Zucker rats are known as 'fa/fa' (which carry the homozygotic mutation of the leptin receptor gene and develop the metabolic syndrome) and 'Lean' (which carry the heterozygotic mutation and do not exhibit the syndrome, and thus act as controls for the ' $\mathrm{fa} / \mathrm{fa}$ ' group). Wistar rats were included as a strain control group. All animals were fed standard diet (PANLAB A04). At 6 months of age all groups were sacrificed and peritoneal leucocytes were obtained. The characterisation of peritoneal subpopulations was carried out by flow cytometry, and two immune function parameters were evaluated: the natural killer activity and the macrophage phagocytosis.

With regard to the peritoneal subpopulations, Zucker 'fa/fa' rats displayed alterations in macrophages, T and B naive lymphocytes with respect to Wistar rats. Natural killer activity, phagocytic index and phagocytic efficacy decreased in leucocytes of Zucker 'fa/fa' rats with respect to Wistar rats. The present results show an impairment of these immune functions in obese Zucker rats, which could indicate that these animals exhibit an older biological age.

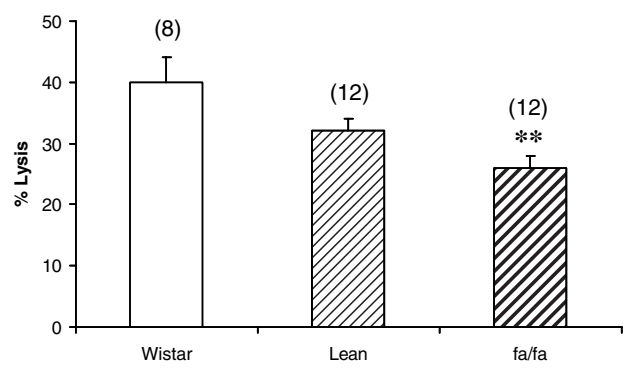

\begin{tabular}{|c|c|c|c|c|c|c|}
\hline \multirow{2}{*}{$\begin{array}{c}\text { Cellular } \\
\text { subpopulations }\end{array}$} & \multicolumn{2}{|c|}{ Wistar } & \multicolumn{2}{c|}{ Lean } & \multicolumn{2}{c|}{ fa/fa } \\
\cline { 2 - 8 } & Mean & SE & Mean & SE & Mean & SE \\
\hline Macrophages & $\begin{array}{c}86.73 \\
(6)\end{array}$ & 2.10 & $\begin{array}{c}90.91 \\
(6)\end{array}$ & 1.22 & $\begin{array}{c}93.56 \\
(6)\end{array}$ & 1.28 \\
\hline Natural killer cells & 2.84 & 0.33 & $\begin{array}{c}6.00 \\
(6) * * *\end{array}$ & 0.49 & $\begin{array}{c}2.58 \\
(6)\end{array}$ & 0.00 \\
\hline Lymphocytes B naive & $\begin{array}{c}(6.20 \\
(5)\end{array}$ & 0.28 & $\begin{array}{c}3.79 \\
(5)\end{array}$ & 0.68 & $\begin{array}{c}4.32 \\
(5)\end{array}$ & 0.54 \\
\hline Lymphocytes T & $\begin{array}{c}13.89 \\
(5)\end{array}$ & 2.97 & $\begin{array}{c}13.01 \\
(5)\end{array}$ & 3.30 & $\begin{array}{c}8.87 \\
(4)\end{array}$ & 1.15 \\
\hline
\end{tabular}
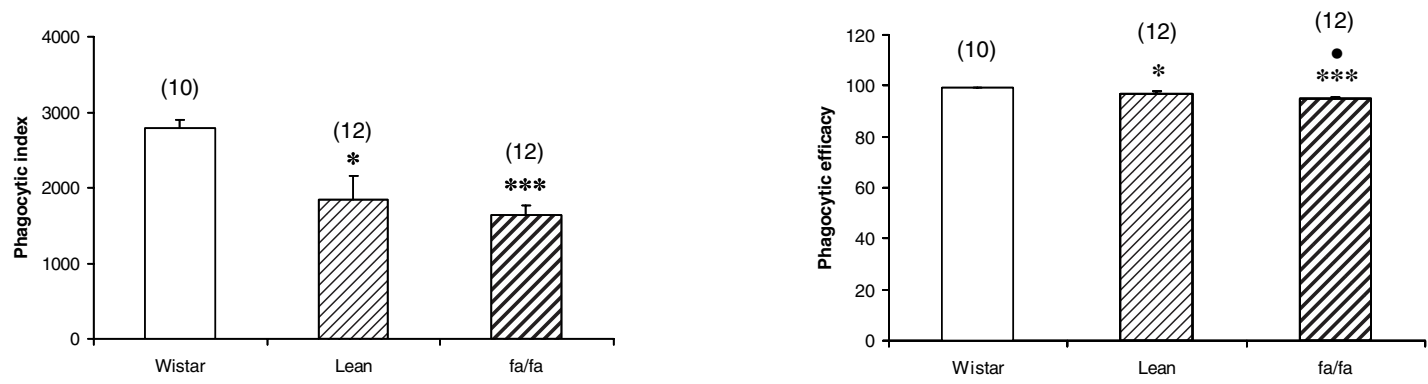

Data are expressed as means \pm SE of the number of animals used (in brackets). $* P<0.05 ; * * P<0.01 ; * * * P<0.001$ with respect to Wistar group. $\bullet P<0.05 ; \bullet \bullet \bullet P<0.001$ with respect to Lean group.

This work was financially support by MEC (DEP2006-56187-CO-02/PREV), UCM Research Group (910379ENEROINN) and RETICEF (RD06/0013/ 0003) (ISCIII) of Spain.

1. Marcos A, Nova E \& Montero A (2003) Eur J Clin Nutr 57 (Suppl 1), S66-S69.

2. De la Fuente M (2008) Neuroimmunomodulation 15, 213-223. 